\title{
La "Ley Sáenz Peña" y su recepción en la legislación electoral de la provincia de Mendoza (1910-1912)
}

\author{
Andrés Abraham *
}

Fecha de Recepción: 15 de mayo de 2021

Fecha de Aceptación: 30 de junio de 2021

DOI: https://doi.org/10.46553/RGES.57.2021.p.234-257

\section{Resumen}

En abril de 1912 Mendoza adoptó los principios de la "Ley Sáenz Peña" mediante la sanción de una nueva ley electoral, convirtiéndose en la primera provincia en receptar su contenido en su legislación local. Pero el proceso reformista comenzó un año antes con otra ley, promovida por el gobernador Rufino Ortega (h), en el marco de su ruptura con su antecesor Emilio Civit y de su alineamiento con la acción reformista del presidente.

El presente artículo reconstruye las coyunturas y las particularidades que signaron la evolución del ordenamiento normativo electoral de la provincia, contextualizando tal proceso en el marco de la reconfiguración de la elite dirigente local que tuvo lugar luego del Centenario. Para ello se examina la morfología de las dos leyes electorales locales del período y los principales cambios que introdujeron en el sistema electoral provincial, junto con el impacto inmediato operado en la dinámica partidaria. Por último, se indaga en torno a la singularidad del proceso reformista mendocino a la luz de lo sucedido en otras provincias.

Palabras clave: Ley Sáenz Peña; Reformismo; Leyes provinciales; Reformas electorales

\begin{abstract}
In april 1912, Mendoza adopted the principles of "Sáenz Peña Law" by enacting new local electoral legislation, becoming the first province to receive its content in its local legislation. But the reformist process began a year earlier, with the proposal of other law, made by Governor Ortega, in the middle of his break with his predecessor -Emilio Civit- and his alignment with the reformist action of the president.

This article reconstructs the junctures and the particularities that marked the evolution of the electoral laws in the province, contextualizing such process within the framework of the reconfiguration of the local ruling elite that took place after the "Centenario". In this framework, we also examine the morphology of the two local electoral laws and the main changes they introduced in the provincial electoral system.

Likewise, the article investigates the assimilation of the new legislation by the local political parties and proposes a reconsideration of the singularity of the Mendoza's reformist process, in light of what happened in other Argentinian provinces.
\end{abstract}

Keywords: Ley Sáenz Peña; Reformism; Provincial legislation; Electoral reforms

\section{Introducción}

La “Ley Sáenz Peña” constituyó un parteaguas en la vida política argentina, al marcar el tránsito de un orden político signado por la acción de una oligarquía a otro de participación

\footnotetext{
* Profesor y Licenciado en Historia (FFyL-UNCuyo). Becario doctoral del Consejo Nacional de Investigaciones Científicas y Técnicas, con lugar de trabajo en el Instituto de Ciencias Humanas, Sociales y Ambientales (INCIHUSA-CONICET, CCT Mendoza). Miembro del Instituto de Historia Americana y Argentina, Facultad de Filosofía y Letras, Universidad Nacional de Cuyo (IHAA-FFyL, UNCuyo), andresabraham@ffyl.uncu.edu.ar
} 
ampliada, abriendo paso con ello a un nuevo escenario de lucha electoral en torno al cual se reconfiguraron los sistemas de partidos, tanto en el país como a nivel subnacional.

Con motivo del centenario de la ley 8.871 diversos estudios revisitaron el contexto de su sanción y el rol de los actores que promovieron la reforma, como también su impacto posterior en el sistema político. Sin embargo, buena parte de estos estudios se centraron en el plano nacional, desconociendo las dinámicas provinciales, un aspecto clave en el trasfondo de la coyuntura político-partidaria que le dio sustento. Al respecto, advierte Míguez:

"Para que Sáenz Peña alcanzara la presidencia y la nueva ley electoral atravesara el Congreso fue necesario aunar la voluntad de un número suficiente de dirigencias provinciales. ¿Por qué consintieron éstas un cambio tan importante? (...). ¿Es que éstas habían perdido gravitación, subordinándose o integrándose a las dirigencias nacionales (lo que no parece muy probable)? ¿O consideraron -no sin cierta razón, al menos en el corto plazo- que este cambio no era crucial para ellas, regidas por sus normas locales? (...)".

La cuestión de las leyes locales y sus reaseguros abre un interrogante sobre la diversidad de respuestas y estrategias de las elites dirigentes lugareñas en los sistemas políticos provinciales, tendientes a emular la reforma nacional, o bien a instaurar algunos resguardos para su predominio. En tal sentido, Fabris, Ferrari y Barbero ${ }^{2}$ mostraron cómo los principios de la reforma de 1912 fueron receptados de forma heterogénea en las leyes electorales provinciales, observándose diversos mecanismos tanto de avenimiento como rechazo a su contenido. En la misma línea Ferrari ${ }^{3}$ advirtió que hubo diversas formas de asimilación -e incluso resistencia- a los cambios en los espacios provinciales, tanto desde las normas electorales locales como desde las prácticas políticas concretas, lo que brinda un escenario variopinto en cuanto a su aceptación fuera del ámbito nacional.

Esta ampliación de la escala de observación -desde la ley nacional a las leyes provinciales- ha permitido complejizar el panorama relativo a la recepción de los postulados, mecanismos y garantías de la reforma saenzpeñista en el orden subnacional. Sin embargo, faltan estudios específicos sobre algunas provincias -entre ellas Mendoza- en el marco de las historias locales y se precisa, además, una síntesis integradora de los trabajos ya existentes, en

\footnotetext{
${ }^{1}$ Eduardo Míguez, "Gestación, auge y crisis del orden político oligárquico en la Argentina. Balance de la historiografía reciente", PolHis 5, 9 (2012): 38-68.

${ }^{2}$ Mariano Fabris; Mauro Ferrari y Héctor Barbero, "El proceso de ampliación del sufragio visto a través de normativas provinciales (1912-1915)", Cuadernos de Historia. Serie Economía y Sociedad, 5 (2002): 65-84.

${ }^{3}$ Marcela Ferrari, "De la nación a las provincias. Adaptaciones de la Ley Sáenz Peña", Estudios Sociales 43, 2 (2012): 183-204.
} 
pos de una mirada más abarcativa del mosaico de respuestas articuladas, tanto desde el orden legal como desde las prácticas políticas y los actores que protagonizaron ese proceso. ${ }^{4}$

Para el caso de Mendoza, el único estudio existente sobre la cuestión aborda la evolución de las leyes electorales desde 1853 hasta 1930, caracterizando los aspectos principales de cada norma. ${ }^{5}$ Por otro lado, se ha abordado el impacto de la reforma saenzpeñista en las prácticas políticas y en las dinámicas de competencia electoral entre 1912 y 1918, pero sin referir al marco normativo ni a la coyuntura que dio origen a la ley local. ${ }^{6}$

En este marco, el presente artículo busca dar cuenta de cómo fue la recepción de los postulados de la reforma saenzpeñista en la legislación electoral mendocina entre 1910 y 1912. Se aborda para ello el contexto de sanción y la morfología de dos leyes provinciales sucesivas, junto con las dificultades suscitadas por la primera de ellas y la coyuntura que llevó a la sanción de una segunda ley. Por último, se reflexiona en torno a las particularidades del proceso reformista local y de la normativa resultante, en relación con otras provincias.

Se plantea como hipótesis que la adhesión temprana de Ortega al ideario reformista presidencial fue una forma de canalizar la oposición de un sector de la elite a la figura preponderante del gobernador saliente -Emilio Civit-, procurando con ello desarticular los mecanismos de fraude y el control de la escena política por parte este. Ello dio curso a un proceso ejemplar de adaptación de la normativa local a los postulados impulsados en el orden nacional, aunque tal proceso no estuvo exento de dificultades y de contramarchas.

Hemos recurrido para nuestro trabajo a las recopilaciones de leyes en la materia, pero no hemos podido hallar los diarios de sesiones legislativas, inexistentes para el período en cuestión en el acervo de la Biblioteca de la Legislatura de Mendoza. Se ha procurado suplir tal faltante por medio de la prensa de la época y los testimonios de miembros de los elencos dirigentes del momento, como José E. Aguilar y Silvestre Peña y Lillo.

\footnotetext{
${ }^{4}$ Constituyen avances en tal sentido, entre otros, los estudios de Loreta Giannone, "La transformación del régimen de representación en la provincia de Córdoba a partir de la aplicación de la ley Sáenz Peña", Quinto Sol, 20, 1 (2016): 1-21.http://dx.doi.org/10.19137/qs0830 (2016); Rubén Correa y Sergio Quintana Villacorta, "Ley Sáenz Peña y reforma electoral provincial en clave oligárquica. Salta, 1912”, Estudios Sociales, 43, 2 (2012): 235-264; María del Mar Solís Carnicer, "Los conservadores argentinos ante el desafío del reformismo y la democratización política: una lectura desde la provincia de Corrientes (1912-1930)". Cuadernos de Historia, 42 (2015): 61-83; Pablo Fernández Irusta, “Apuntes teóricos e historiográficos sobre el proceso de democratización en la provincia de Buenos Aires (1912-1930)", XI Jornadas Interescuelas/Departamentos de Historia (Universidad Nacional de Tucumán, San Miguel de Tucumán, 2007) y Nicolás Motura, "De la República Restrictiva a la República Democrática. El caso de la Reforma Electoral en Entre Ríos (1912-1914)”, Tesina de Licenciatura en Ciencia Política (Universidad Autónoma de Entre Ríos, Paraná, 2020).

5 María Cristina Seghesso, "El régimen electoral en la provincia de Mendoza desde la Ley Sáenz Peña a 1930", Revista de Historia del Derecho 9 (1981): 373-413 e "Historia del régimen electoral mendocino anterior a la Ley Sáenz Peña (1853-19120)", Revista de Historia del Derecho, 16 (1988): 429-485.

${ }^{6}$ Beatriz Bragoni y Virginia Mellado, "Civitistas, populares, radicales y lencinistas: partidos y competencia electoral en Mendoza (1912-1918)”. Estudios Sociales 43, 2 (2012): 205-233.
} 


\section{La elite dirigente mendocina en los prolegómenos de la reforma}

Desde la década de 1880 hasta el Centenario, la provincia de Mendoza vivió una serie de cambios que modificaron su fisonomía. La adopción del modelo vitivinícola transformó la matriz productiva mendocina y permitió su inserción exitosa en el modelo agroexportador a nivel nacional, logrando un importante crecimiento económico. ${ }^{7}$ Hubo, además, una metamorfosis en el plano social, merced al arribo de contingentes inmigratorios que modificaron la composición de la sociedad criolla local, se insertaron en el mercado de trabajo vitivinícola e incidieron en los patrones de poblamiento de los oasis de la provincia. ${ }^{8}$

Hacia 1910 Mendoza había transformado radicalmente su economía y su estructura socio-demográfica, pero seguía aferrada en lo político a un modelo restrictivo. La provincia estuvo regida durante esos años por una oligarquía, que instauró su dominio sobre la base de concesiones de derechos de riego, subsidios oficiales discrecionales (por vía de la banca provincial o la entrega de tierras públicas) y del accionar de la policía con fines políticos. Respecto de los elencos políticos, entre 1880 y 1905 unas veinte familias -con lazos de parentesco o matrimonio- monopolizaron los cargos públicos y construyeron redes -locales y nacionales- que retroalimentaron su capital político y simbólico. ${ }^{9}$

Dentro de esa oligarquía, se destacó -como primus inter pares- la familia de Emilio Civit, ${ }^{10}$ cuyos vínculos estrechos con las máximas figuras del Partido Autonomista Nacional lo posicionaron como líder indiscutible y "gran elector" en el orden político provincial. Su predominio, insoslayable desde 1898, desarticuló la acción de un incipiente movimiento reformista que había surgido en Mendoza hacia 1879 para propiciar el saneamiento de las prácticas políticas y el respeto por el sufragio libre. Este impulso reformista operó en las

\footnotetext{
${ }^{7}$ Rodolfo Richard-Jorba, Poder, Economía y Espacio en Mendoza, 1850-1900. Del comercio ganadero a la agroindustria vitivinícola (Mendoza:EDIFYL, 1998).

${ }^{8}$ Juan Manuel Cerdá, Condiciones de vida y vitivinicultura. Mendoza, 1870-1950 (Bernal: Universidad Nacional de Quilmes, 2007).

${ }^{9}$ Véase: Joan Suplee, "Water, guns, and money: the art of political persuasion in Mendoza (1890-1912)", en Brennan, James y Pianetto, Ofelia. Region and Nation: Politics, Economics, and Society in Twentieth-Century Argentina (New York: Palgrave Macmillan, 2000), pp. 49-69. http://dx.doi.org/10.1007/978-1-349-62844-5.

${ }^{10}$ Emilio Civit (1856-1920) fue un dirigente conservador, hijo del ex gobernador Francisco Civit. Fue Diputado Nacional (1882-1889), Senador Nacional (1891-1892) y Ministro de Gobierno Provincial (1895-1898). Resultó electo gobernador en 1898, pero renunció para ser designado ministro de Roca. Luego fue elegido nuevamente gobernador, por el período 1907-1910 y de ahí pasó al Senado Nacional (1910-1919). Alineado con el roquismo, fue la figura de mayor ascendiente sobre la clase política local. Véase: Dardo Pérez Guilhou, Ensayos sobre la historia política institucional de Mendoza. (Buenos Aires: Imprenta del Senado de la Nación, 1997), pp. 151170.
} 
últimas décadas del siglo XIX, de la mano de figuras disidentes de los elencos gobernantes que se anticiparon al denominado "Reformismo del Centenario", como Julián Barraquero. ${ }^{11}$

En lo que respecta a la participación electoral, la apatía era la característica saliente de los comicios de entonces, que solían ratificar lo decidido en los cenáculos de notables. Por otro lado, el civitismo puso en práctica otras argucias que neutralizaron cualquier atisbo de oposición. ${ }^{12}$ Resulta ilustrativa la descripción hecha por Barraquero en 1908, al presentar como diputado nacional un proyecto de intervención a Mendoza, por considerar subvertida la independencia de los tres poderes locales. Allí expresaba que desde el ascenso de Civit los partidos opositores no habían concurrido a ninguna elección (nacional, provincial ni municipal) y que reinaba en la Legislatura la unanimidad absoluta, sin que hubiera un solo opositor en las cámaras. Refería también a diversos atropellos a la justicia y denunciaba el desconocimiento de la autonomía del Departamento de Irrigación, como así también el excesivo peso presupuestario que tenía la policía provincial y el incremento numérico de sus efectivos, envergadura que atribuye a delirios persecutorios del primer mandatario. ${ }^{13}$

En los prolegómenos del ascenso de las ideas reformistas, el propio Civit promovió mediante una reforma constitucional algunos cambios en materia electoral. En esa oportunidad propuso implementar un Registro cívico provincial permanente y habilitar el restablecimiento del sistema proporcional para la elección de Diputados provinciales. Pero hubo quienes recelaron de las verdaderas intenciones del primer mandatario, previendo que las propuestas eran sólo una fachada y que la ley reglamentaria volvería ineficaces los

\footnotetext{
${ }^{11}$ Véase: Beatriz Bragoni, "Prácticas políticas, coaliciones gubernamentales y cambio institucional: la fragua de la rivalidad entre partidos en el ciclo de reformas constitucionales provinciales, Mendoza, 1889-1900". Estudios Sociales, 51, 2 (2016): 31-61. 2016). Julián Barraquero (1856-1935) fue un destacado jurista y constitucionalista mendocino, de orientación krausista, que ocupó diversos cargos políticos y en la función pública local y en la Provincia de Buenos Aires. Se desempeñó como diputado nacional por Mendoza en tres períodos (1898- 1910), alineándose con el sector reformista. En 1911 se integró al Partido Popular- y ocupó la cartera de Gobierno bajo mandato de Rufino Ortega (en abril de 1912) y luego con Francisco Álvarez (de 1914 a 1916). En sus últimos años fue Procurador de la Suprema Corte de Justicia y fiscal de Estado. Gobierno de Mendoza. Dr. Julián Barraquero, su labor parlamentaria y jurídica (Buenos Aires: Talleres Gráficos de L. Gutiérrez, 1926).

${ }^{12}$ Un ejemplo de ello es el derrotero de la Unión Democrática, agrupación opositora creada en 1904, que nucleó a destacadas figuras como Exequiel Tabanera (h), Juan Serú, Severo del Castillo, los hermanos Calle (dueños del Diario Los Andes) o el empresario Honorio Barraquero. Su concurrencia a comicios en 1905 y 1906 demostró a sus dirigentes la imposibilidad de hacer frente al fraude y a la acción policial con la que Civit manejaba los actos electorales. La entidad se desarticuló hacia 1907, quedando parte de su dirigencia vinculada con el Partido Constitucional -sigla creada por jóvenes que se escindieron del civitismo-, confluyendo en una coalición electoral que impulsó la candidatura del General Rufino Ortega para las elecciones de gobernador de 1907, la cual fue magistralmente desarticulada por Civit. Sanjurjo, Inés Elena, "Formación de una elite de inmigrantes y criollos en el departamento de San Rafael (Mendoza) y su incidencia en la política provincial en los prolegómenos de la sanción de la ley Sáenz Peña”, Res Gesta, 45 (2000): 109-148.

${ }^{13}$ Gobierno de Mendoza, Dr. Julián Barraquero..., pp. 449-461.
} 
cambios en la práctica. Por otro lado, se consagraron algunos resguardos para el predominio del gobernador sobre los demás poderes y sobre el régimen municipal. ${ }^{14}$

En virtud de su aura de autoridad incontestable por el manejo eficaz de los resortes del poder, Civit pudo imponer un candidato propio para sucederlo en la gobernación. El elegido fue Rufino Ortega (hijo), ${ }^{15}$ por entonces diputado provincial y Jefe de Policía, con quien tenía además un nexo familiar indirecto. ${ }^{16}$ Con su apadrinamiento en el seno de los Partidos Unidos ${ }^{17}$ se apuntaba contra el general Rufino Ortega, cuya candidatura opositora tenía el apoyo del presidente Figueroa Alcorta. La maniobra -que emulaba la argucia de Roca al promover a Luis Sáenz Peña en 1892- tuvo éxito y el padre declinó su postulación. Esto le garantizó a Civit la imposición de su elegido como sucesor -sin oposición- y la continuidad de su predominio, reflejada luego en su elección como Senador nacional, en abril de $1910 .{ }^{18}$

Sin embargo, a comienzos de 1911 se formó una nueva agrupación opositora -el Partido Popular-, integrada por dirigentes conservadores de tendencia reformista que habían formado parte de agrupaciones políticas contrarias al oficialismo (las mencionadas Unión Democrática y el Partido Constitucional, como así también la Coalición Electoral, el Partido Independiente, la Liga Cívica y el partido Unión Nacional). Este nuevo partido promovió el lanzamiento de la candidatura del industrial Pedro Benegas a diputado nacional, en clara oposición a la continuidad de los manejos de Civit.

Por su parte, el radicalismo se hallaba fragmentado en ese entonces en dos tendencias principales: un sector "moderado", comandado por el ex gobernador Pedro N. Ortiz - aliado al civitismo desde 1895, cuando se sumó a los "Partidos Unidos"- y un sector revolucionario o "rojo" que respondía a José Néstor Lencinas y se mantenía en la abstención. ${ }^{19}$ En el contexto de la reforma, hacia abril de 1912 la línea "orticista" rompió con Civit y logró el respaldo del

\footnotetext{
${ }^{14}$ Véase: Ana María Mateu, "La Constitución de la provincia de Mendoza de 1910", Revista de Historia del Derecho, 8 (1980): 247-311 y Carlos Egües, Historia constitucional de Mendoza. Los procesos de reforma (Mendoza: EDIUNC, 2008).

${ }^{15}$ Félix Rufino Ortega Ozamis (1872-1933) era hijo del General Rufino Ortega (gobernador entre 1884 y 1887) y de Elvira Ozamis, de familia acomodada en la zona de Maipú. Luego de egresar del Colegio Nacional de Buenos Aires, regresó a la provincia a regentear junto a su hermano Roberto la firma vitivinícola "Ortega Hnos.", propietaria de la bodega "La Libertad" y de fincas en el departamento de Rivadavia. Fue concejal en ese departamento (1905-1907) y luego diputado provincial y Jefe de la policía provincial. Jaime Correas, Historias de familias (Mendoza: Primera Fila-Diario Uno, 1992).

${ }^{16}$ Los Ortega y los Civit quedaron vinculados por el lazo matrimonial de Julio, el hijo menor del general Ortega, que contrajo matrimonio con Josefina, hija de Civit. Jaime Correas, Historias de familias..., p. 45. Bragoni y Mellado sindican erróneamente a Rufino Ortega como yerno de Civit, pero el vínculo matrimonial correspondió a su hermano menor. Bragoni y Virginia Mellado, “Civitistas, populares, radicales y lencinistas ..., .p. 212.

${ }^{17}$ Los "Partidos Unidos" fueron una coalición electoral que sirvió de sustento político a Civit desde 1898, formada por el Partido Cívico (Unión Cívica), el Partido Independiente y el Partido Liberal (civitista).

${ }^{18}$ Lucio Funes, Gobernadores de Mendoza: la oligarquía, (Mendoza: Best Hermanos, 1942), p. 133.

19 Pablo Lacoste, La Unión Cívica Radical en Mendoza y en la Argentina, 1890-1946 (Mendoza: Ediciones Culturales de Mendoza, 1994), p. 32.
} 
grupo liderado por Exequiel Tabanera (h), mientras que por la misma época el sector "rojo" sufrió la escisión de un núcleo encabezado por Jesús Romero (figura de la revolución radical de 1905), descontento con el accionar personalista y arbitrario de Lencinas en el partido.

\section{La reforma de Sáenz Peña y su proyección temprana en Mendoza}

La reforma electoral promovida por Roque Sáenz Peña a nivel nacional implicó la sanción correlativa de tres proyectos de ley. Los dos primeros fueron presentados en el Congreso el 17 de diciembre de 1910 y el tercero el 11 de agosto de 1911, una vez aprobados los anteriores. Se dejó así para el final la discusión sobre la ley nacional de elecciones, intertanto se elaboraba un nuevo padrón electoral, que se pondría a prueba en las elecciones de diputados nacionales previstas para marzo de $1912 .^{20}$

El primer proyecto dispuso un nuevo enrolamiento militar general de los ciudadanos varones en el marco de la "Ley Ricchieri" (y la creación de un registro militar a partir de 58 distritos militares y mil oficinas enroladoras). Por el segundo se encargó a la justicia federal la elaboración de los padrones electorales sobre la base de los registros de enrolamiento remitidos por el Ministerio del Interior. Estos dos proyectos fueron sancionados por el Senado en julio de 1911 y se promulgaron como leyes $n^{\circ} 8.129$ y 8.130 .

Finalmente, el 13 de febrero de 1912, se sancionó la ley 8.871, que introdujo como novedades el voto secreto y obligatorio para todas las elecciones convocadas por las autoridades nacionales y la centralización de los escrutinios. Esto implicó dejar la apertura de las urnas y recuento de los votos a cargo de juntas escrutadoras nacionales en cada distrito, integradas en cada provincia por miembros del Poder Judicial. Asimismo, se dispuso la adopción del sistema electoral de lista incompleta para diputados y electores de Presidente, con lo que se concedía representación fija de un tercio a la primera minoría de cada distrito.

A partir de febrero de 1912, comenzó un proceso de recepción de los postulados de la nueva ley en las normativas electorales provinciales, operando principalmente en tres planos: la delimitación del sujeto de derecho electoral, el sistema electoral y la composición y atribuciones de las juntas electorales. ${ }^{21}$

Mendoza se adelantó a la tarea de adaptación de su normativa sancionando una nueva ley provincial en mayo de 1911, que reflejó el temprano alineamiento político del gobernador

\footnotetext{
${ }^{20}$ Mario Justo López, De la república oligárquica a la república democrática. Estudio sobre la reforma política de Roque Sáenz Peña (Buenos Aires: Lumière, 2005), p. 241.

${ }^{21}$ Mariano Fabris, Mauro Ferrari y Héctor Barbero, El proceso..., p. 69.
} 
Ortega con Sáenz Peña. Pero luego se constataron algunos problemas prácticos que obstaculizaron su aplicación y la promulgación de la ley 8.871 dio pie a un consenso proclive a la adopción íntegra de la ley nacional para el orden local. En ese contexto, se manifestó una confluencia de las posiciones de la dirigencia política en torno a la "cuestión electoral".

\section{La ley $n^{\circ}$ 567: la avanzada reformista de Ortega}

Rufino Ortega (h) asumió como gobernador el 6 de marzo de 1910. Pronto se convenció de la necesidad de romper con las prácticas y el influjo de Civit para enrolarse en la cruzada reformista del presidente Sáenz Peña. De hecho, para los festejos del Centenario ya existía un núcleo de dirigentes conservadores que consideraban perimido el liderazgo de Civit y sugerían a Ortega buscar un respaldo alternativo que neutralizara su preeminencia. ${ }^{22}$

En ese escenario, el gobernador elevó a la Legislatura -en abril de 1911- un proyecto de nueva ley electoral provincial, que fue tratado sobre tablas y finalmente quedó promulgado el 5 de mayo, como ley $n^{\circ} 567 .{ }^{23}$ La autoría del anteproyecto correspondió a Manuel Lemos, reconocido abogado del foro local y ex funcionario allegado al gobernador, quien realizó un estudio previo de la legislación anterior y remitió su borrador a figuras destacadas del ámbito local para obtener su parecer, entre ellos el propio Barraquero. ${ }^{24}$

En los fundamentos de su mensaje a las cámaras, el gobernador recurrió a apreciaciones propias del ideario reformista -mostrándose ya alineado con el presidente-. ${ }^{25} \mathrm{La}$ libertad de sufragio se presentaba como una necesidad vinculada al progreso económico:

\footnotetext{
${ }^{22}$ Dardo Pérez Guilhou, Ensayos..., p. 160.

${ }^{23}$ El trámite parlamentario fue expeditivo: el proyecto ingresó a Diputados el 17 de abril, fue tratado sobre tablas y aprobado. Pasó a Senadores el 24 de abril, donde también se analizó sobre tablas y se aprobó en general, en una sesión especial, sin lectura previa del proyecto. Finalmente, luego del debate particular, se sancionó en dicha cámara el día 3 de mayo (Los Andes, 18/04/1911 y 25/04/1911).

${ }^{24}$ Los Andes, 13/04/1911. Lemos era Ministro de Industrias y Obras Públicas de Ortega, pero renunció en febrero de 1911. Había elaborado un trabajo sobre la situación de la industria titulado "La cuestión vitivinícola de Mendoza", que sirvió de base para su acción como funcionario. Diario Los Andes, Cien años de vida mendocina, 1882-1982 (Mendoza: Imprenta Hermanos Calle S.A., 1982), p. 54.

${ }^{25} \mathrm{Si}$ bien no hemos hallado registros epistolares, existían vínculos previos entre las familias del gobernador y del presidente que pudieron facilitar tal alineamiento político. En primer lugar, la esposa de Roque Sáenz Peña Rosa Isidora González Delgado- había nacido en Mendoza en 1857 y era sobrina de Carlos González Pintos (1830-1916), ex gobernador y patriarca de una de las familias tradicionales de la oligarquía local. Por otro lado, el ex presidente Luis Sáenz Peña había adquirido hacia 1900 una finca con un molino en el distrito La Libertad (Rivadavia) y vivió allí durante algunos años, en compañía de su hija Cipriana, siendo recordados en la localidad por la promoción de actividades sociales y culturales. En ese marco, es muy probable que entablasen algún tipo de vínculo con los hermanos Ortega-Ozamis (Rufino y Roberto), propietarios de la bodega aludida y de viñedos en esa localidad. Asimismo, el general Ortega habría facilitado a Sáenz Peña mano de obra servil para su finca, proveniente de indígenas capturados en la "Campaña del Desierto". Véase Delrío, Walter y Escolar, Diego, "Trayectorias y memorias de la diáspora forzosa de prisioneros indígenas entre Patagonia y Cuyo SXIX-XX", XII Jornadas Interescuelas/Departamentos de Historia (Bariloche, San Carlos de Bariloche, 2009).
} 
"Mendoza, que avanza victoriosamente en el orden de los adelantos materiales, debe incorporarse también a semejante movimiento de reconquista de los derechos ciudadanos, sintetizados en la urna genuina, proscribiendo, sin vacilaciones, las causas que puedan adulterarla o falsearla; a fin de que, poseedora de suelos y veneros fecundos en riquezas de matices varios, cuya divulgación viene provocando el interés del mercado universal, ofrezca, de las primeras, a la vez el ejemplo de la mayor confianza por el respeto inalterable a los principios y a las leyes dirigentes de su organización $(\ldots)$ ". ${ }^{26}$

El mensaje ponía luego énfasis en la necesidad de promover el interés de la población en las cuestiones públicas, por intermedio las "fuerzas populares organizadas". Se identificaba así a los partidos políticos como canales de expresión de la voluntad popular y se consideraba imprescindible fomentar la creación de partidos orgánicos e impersonales, cuya misión no fuera "atentar contra la existencia de los poderes", sino controlar de cerca su marcha.

En ese marco, Ortega señaló que una de sus propuestas era dar representación de "todas las opiniones" por medio de la proporcionalidad, procedimiento que "satisfaría las exigencias populares" y que contaba con amplio "respaldo científico". ${ }^{27}$ Por otro lado, se estipulaban duras penas a las infracciones a la ley, propendiendo con ello al castigo enérgico y rápido de los intentos de falsear la norma en la práctica. ${ }^{28}$

El proyecto de Ortega recibió prontamente el beneplácito presidencial, reflejado en un intercambio de telegramas entre ambos mandatarios. ${ }^{29}$ El 23 de abril, el presidente envió un telegrama oficial ensalzando a la reforma mendocina por considerarla una vía hacia "una política amplia de libertad y garantía" electorales y advirtió su preocupación por "ver logradas en los estados federales la verdad del sufragio y la representación de las minorías". ${ }^{30}$

Como respuesta, Ortega agradeció la “conceptuosa felicitación” enviada por el presidente, y ratificó su voluntad de hacer cumplir el programa de libre sufragio, destacando notas del proyecto como el amparo al voto libre y "la representación ordenada y proporcional de todas las opiniones". Expresó, además el estímulo que significaba el respaldo nacional a su

\footnotetext{
${ }^{26}$ Provincia de Mendoza, Recopilación de leyes de la Provincia de Mendoza, sección correspondiente al Ministerio de Gobierno (Mendoza: Larrea y Benzoni, 1925), tomo III, p. 1089.

${ }^{27}$ Este sistema de representación ya había sido adoptado en la Constitución provincial de 1895, y tuvo vigencia hasta que Civit promovió en el año 1900 una nueva reforma y lo dejó de lado.

${ }^{28}$ Provincia de Mendoza, Recopilación ..., p. 1091.

${ }^{29}$ Esta conducta de Sáenz Peña anticipó la estrategia que implementó luego de la sanción de la ley n ${ }^{\circ} 8.871$ para garantizar el éxito de la reforma en las provincias, la cual combinó la persuasión, las advertencias y las amenazas a los gobernadores. Mario Justo López, De la república ..., p. 327.

${ }^{30}$ Los Andes, 25/04/1911.
} 
acción, dificultada en el orden provincial por "ambiciones de círculos e intereses personales" y por la reacción de quienes seguían aferrados a "viejas prácticas" en la vida pública. ${ }^{31}$

La nueva norma aprobada constaba de 129 artículos, distribuidos en 5 títulos. Entre los cambios más importantes estuvieron la creación de un Registro Cívico permanente, que serviría de base para la confección de los padrones de las elecciones provinciales y que debía ser renovado cada año. La tarea de formación y actualización quedaba a cargo de comisiones inscriptoras ad hoc, ${ }^{32}$ integradas por ciudadanos nombrados por la Junta Electoral. ${ }^{33}$

Los requisitos previstos en la ley $n^{\circ} 567$ para integrar las comisiones dan cuenta de la firme intención de Ortega de regularizar la elaboración del padrón -sustrayéndolo definitivamente del influjo de las agrupaciones políticas y/o del gobierno-. Pero el procedimiento previsto para su conformación era bastante engorroso: por cada distrito electoral la Junta debía elegir por sorteo público a 6 ciudadanos alfabetizados, que fuesen contribuyentes del fisco, mayores de edad, que no fuesen empleados públicos y que residiesen en el lugar con al menos 2 años de antigüedad. Acto seguido, se debía sortear con el mismo sistema una lista de 5 ciudadanos para conformar el "Jury de tachas", junta encargada de resolver reclamos en torno a la labor de las comisiones. ${ }^{34}$

En cuanto a la proclamación de las listas de candidatos, se exigía la presentación previa de carta orgánica y nómina de autoridades de los partidos que iban a competir, aunque se excluía expresamente a las agrupaciones anarquistas. Para Diputados y electores de Gobernador, se consagró la "lista bloqueada" impidiendo alterar el orden de los candidatos aprobado por la Junta Electoral. Sin embargo, daba la alternativa al elector independiente de armar su propia lista integrando candidatos de varias listas proclamadas.

Otras particularidades relativas al comicio eran la exigencia reglamentaria de una "doble llave" para cada urna, la elección del presidente de mesa in situ, a "simple mayoría" (entre 5 escrutadores sorteados) y la disposición de un doble escrutinio. Esto último obligaba a un conteo de votos en el lugar de la votación, una vez cerrado el comicio, cuyos resultados

\footnotetext{
${ }^{31}$ Los Andes, 27/04/1911.

${ }^{32}$ Tal sistema rigió a nivel nacional hasta 1911. Otras alternativas eran la confección por las municipalidades, por las autoridades judiciales, por el registro civil o por comisiones de electores. Mario Justo López, De la república..., p. 242.

${ }^{33}$ La Junta, máxima autoridad en la materia, quedaba integrada por el presidente de la Suprema Corte de Justicia provincial y los presidentes de las cámaras de Senadores y Diputados. La presidencia quedaba en manos del primero, pero los miembros de origen "político" tenían mayoría para las votaciones.

${ }^{34}$ Los ciudadanos sorteados no podían excusarse de su función -salvo causales extremas-, y estaban obligados a cumplir sus funciones todos los domingos y días festivos desde el 1 de octubre al 31 de diciembre de cada año, "sin interrupción alguna", de 7 a 12 horas. Las comisiones debían elaborar cuadernos con hasta 200 ciudadanos y emitir una "partida cívica" para entregarla a cada elector inscripto, como documento a presentar para votar.
} 
se enviaban a la Junta Electoral por medio del correo. Luego dicha Junta realizaba el escrutinio general, una vez recibidas todas las urnas y resueltas las impugnaciones de mesas.

En materia de representación, fijaba la proporcionalidad para Diputados y electores de gobernador, por medio del sufragio combinado por listas y coeficiente electoral. ${ }^{35} \mathrm{~A}$ tales efectos, se dividía a la provincia en tres distritos electorales (artículo 16), que agrupaban a los departamentos por entonces existentes (figura 1).

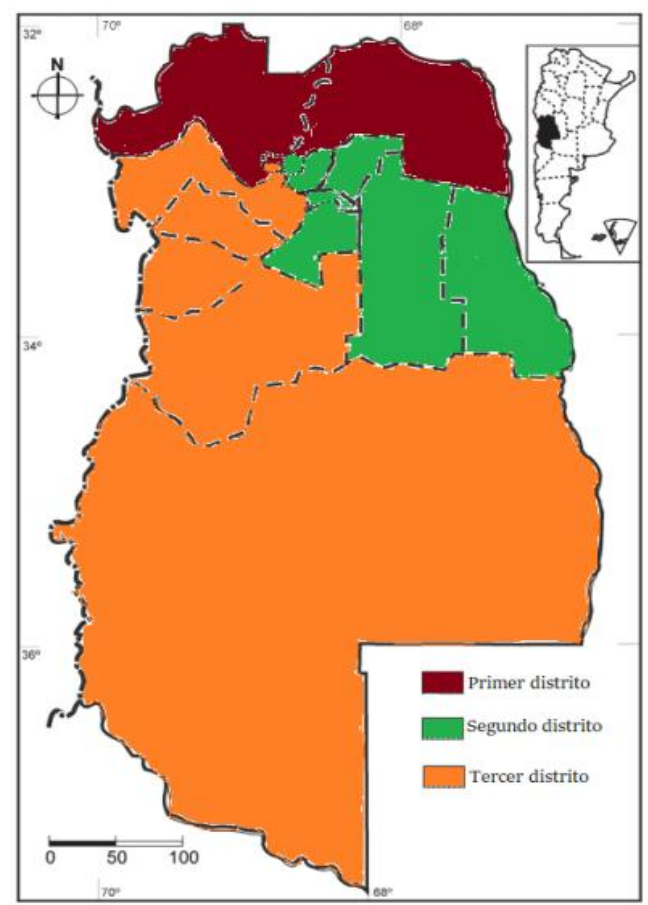

Figura 1: Distritos electorales para Diputados y electores de Gobernador

El primer distrito abarcaba los departamentos de Capital, Las Heras y Lavalle; el segundo a Guaymallén, Maipú, San Martín, Santa Rosa, La Paz, Rivadavia y Junín; el tercero a Godoy Cruz, Luján, Tupungato, Tunuyán, San Carlos y San Rafael (que en ese entonces incluía los actuales territorios de General Alvear y Malargüe). Al primer distrito correspondía elegir 8 diputados, al segundo 9 y al tercero 8.

\footnotetext{
${ }^{35}$ Discrepamos aquí con Seghesso, quien caracteriza este mecanismo como "Sistema de Hagenbach", pues tal sistema implica la división del total de sufragantes por el número de bancas "más uno", algo que no se prevé en este caso. Lo que se adoptó es el sistema "Hare-Borèly" o de "doble cociente", que incorpora a la proporción el criterio partidario. Se parte de la división de los votos totales emitidos por el número de bancas a distribuir, cuyo resultado es un cociente. Luego se otorga a cada lista un número de bancas equivalente a las veces que sus candidatos logran el cociente, según su cantidad individual de votos. Por último las bancas no distribuidas son asignadas a las listas que tienen el mayor remanente de votos ("resto mayor"). Este sistema reconocía como antecedente de aplicación en nuestro país la ley bonaerense de 1876 y en Mendoza había sido propuesto por Barraquero, con una redacción muy similar a aquella. Véase: María Cristina Seghesso, Historia del régimen electoral mendocino ..., p. 377 y Leonardo Hirsch, "La República proporcional en Buenos Aires (1890-1898). La consagración de los partidos políticos en la Argentina" (Tesis de Doctorado en Historia, Universidad de Buenos Aires, Buenos Aires, 2016).
} 
Por su parte, la elección de senadores se mantiene el criterio fijado en 1895, realizándose a "simple pluralidad de sufragios", a razón de 1 por cada departamento y por la capital, conforme al artículo 27 de la Constitución provincial de 1910. Dicha cámara quedaba conformada así por 16 integrantes, con miembros elegidos en "secciones" (figura 2).

Por último, se destaca la disposición de fuertes sanciones - penas pecuniarias o arresto, según el caso- contra quienes cometieran transgresiones al derecho electoral, tanto en torno a la acción de las comisiones inscriptoras y los jury, como en todo lo relativo al comicio en sí. Los procedimientos se incoaban ante la Justicia del crimen provincial, debían ser expeditivos -se preveían multas a los funcionarios judiciales en caso de "retardo de justicia"- y se consideraba a tales delitos objeto de acción pública, a cargo del Ministerio Fiscal.

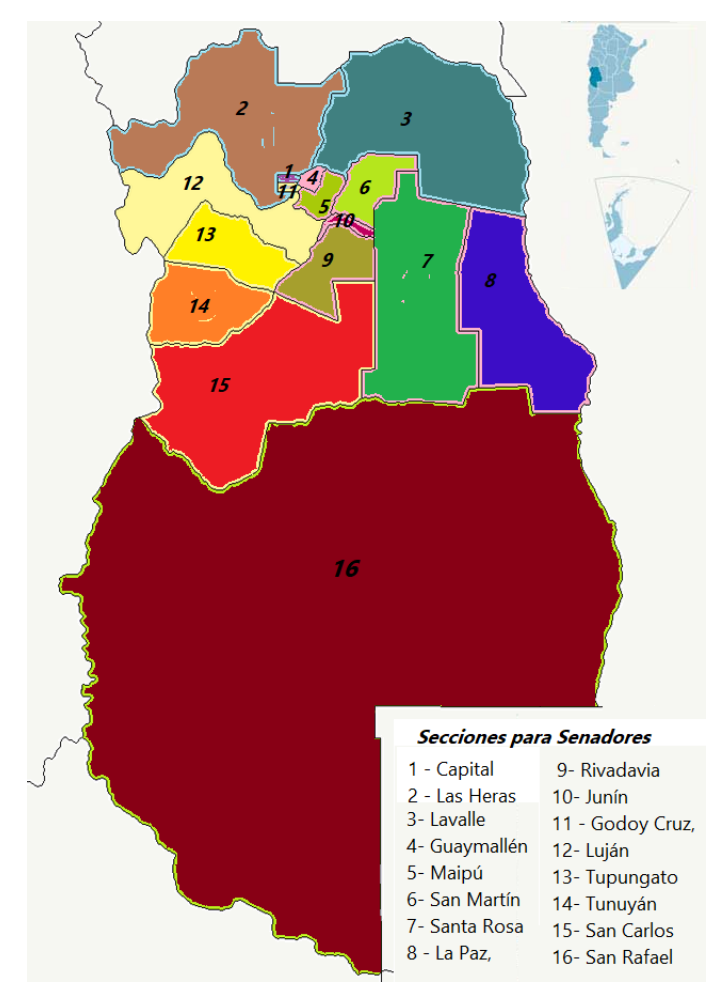

Figura 2: secciones electorales para elección de Senadores

Como contrapartida, sin embargo, la ley contenía algunas pautas todavía conservadoras en relación con el ideario saenzpeñista, por ejemplo no contemplaba aún ni la obligatoriedad ni el carácter secreto del voto. Lo primero se explica por la tradición local en materia de sufragio, pues en varias oportunidades la elite propició el voto calificado. ${ }^{36}$

\footnotetext{
${ }^{36}$ El carácter y la evolución del sufragio mendocino en el siglo XIX han sido analizados por María Cristina Seghesso, El régimen electoral...., pp. 449-466. Dicha autora plantea que desde la carta magna local de 1854 imperó en la dirigencia local una vocación restrictiva en materia de derechos políticos, lo que se vio reflejado en la inclinación de la legislación electoral a consagrar el voto calificado -originalmente sobre la base de la condición de propietario, contribuyente al fisco y/o al ejercicio de una profesión liberal- y luego, desde 1860,
} 


\section{Dificultades intrínsecas de la ley, quejas opositoras y adopción del padrón nacional}

En junio de 1911 se creó en el ámbito del Ministerio de Gobierno una oficina especial, la "Sección electoral", con el objetivo de asignar a tal agencia todas las tareas que se atribuían al Ejecutivo en la materia. ${ }^{37}$ Asimismo, se le encargó la función de reunión y recopilación de información estadística electoral. El decreto de Ortega justificaba la medida advirtiendo que era indispensable para tales tareas una especial "prolijidad, dedicación y exactitud", algo que no podía cumplirse con la dotación de personal existente por entonces en el Ministerio. ${ }^{38}$

Sin duda, la creación de esta dependencia muestra la intención del gobierno de constituir un plantel permanente para hacer efectivas las garantías prometidas. Pero cabe pensar que la dotación prevista resultó insuficiente, pues se asignaron sólo tres empleados (1 jefe y dos auxiliares), para funciones complejas y variadas, que debían cubrir todos los rincones de la provincia y con un elevado grado de dificultad en los procedimientos.

Resultan ilustrativas al respecto los escollos similares que se observaron por entonces respecto del padrón nacional. ${ }^{39}$ En Mendoza, la justicia federal trabajó contra reloj en la elaboración del mismo, afectando personal especial a la tarea, que se inició el 15 de diciembre de 1911 y concluyó en marzo de 1912, bajo los lineamientos de la ley 8.130 y las indicaciones del Ministerio del Interior. En ese marco, el juez federal que presidía la Junta nacional -el Dr. Toribio Lucero- calificó al padrón local como "uno de los mejores o más completo que se han preparado en la República". Sin embargo, reconoció que su elaboración fue dificultosa y se vio resentida, tanto por el apremio de los plazos legales, como por la escasez del personal y por su relativa competencia para ello, siendo su remuneración escasa. Asimismo, consideró

\footnotetext{
con la obligación de saber leer y escribir. Estos requisitos fueron observados por el Congreso de la Nación hacia 1865, dado que contradecían la universalidad del voto que gozaba de rango constitucional, y fueron modificados para no entrar en colisión con la normativa electoral nacional. Pero la vocación restrictiva vuelve a hacerse presente en los proyectos de Julián Barraquero, que tendrán gran relevancia pública entre 1881 y 1916.

${ }^{37}$ Las tareas previstas por la nueva norma incluían la formación del Padrón Cívico provincial, las inscripciones de partidos y candidatos y otros requerimientos conducentes al proceso electoral en sí: remisión de padrones a la Junta Electoral, publicidad de las convocatorias y resolución de excusaciones de autoridades de mesa. Asimismo, para el día del comicio se encargaría de la distribución en cada mesa de votación de las urnas -con sus correspondientes llaves-, boletas, formularios y otros materiales.

${ }^{38}$ Véase el decreto, con fecha 1 de junio de 1911, en Provincia de Mendoza, Recopilación..., pp. 1132-1133.

${ }^{39}$ Corresponde remitir a dos reformas que se promovieron a nivel nacional a la ley $n^{\circ} 8.129$. La primera preveía una extensión de 4 meses en los plazos previstos para la confección de los padrones nacionales en cada distrito y la segunda incrementaba las retribuciones monetarias para los jefes del Registro Civil abocados a la confección de los mismos (Mario Justo López, De la república..., p. 246).
} 
que era difícil hallar personal calificado para la tarea, pues las exigencias iban más allá de las condiciones personales de los empleados. ${ }^{40}$

La sanción de la ley en 8.871 en febrero de 1912 y la correcta marcha de la reforma nacional según los pasos previstos crearon un clima de efervescencia política en Mendoza, acrecentando las exigencias de garantías por parte de los partidos locales. La primera experiencia de elecciones bajo la nueva legislación nacional se convocó para el 7 de abril, debiendo elegirse en Mendoza un diputado nacional, con el padrón elaborado por la Junta Escrutadora nacional constituida en la provincia. ${ }^{41}$

Ante tal panorama, comenzaron a evidenciarse diversos obstáculos en la implementación de la ley provincial. De hecho en la propia norma se condicionaba su puesta en práctica a la finalización del registro cívico local, cosa que no llegó a ocurrir. ${ }^{42}$ La dificultad principal para ello estribó en los problemas prácticos derivados del aludido procedimiento exigido para el nombramiento de las comisiones inscriptoras y jurys, e igualmente de las exigencias y el reglamentarismo en torno a su labor, lo que dilató y obstaculizó la confección del Registro y la posterior elaboración de los padrones sobre la base de este. Amén de la insuficiencia de personal de la "Sección electoral", la conformación de dichas juntas se tornó sumamente difícil porque implicaba afectar mediante una "carga pública" -sin remuneración alguna- a ciudadanos sorteados, durante un lapso de tiempo considerable, en una labor que tenía cierta complejidad desde lo administrativo.

Debido a las demoras en la elaboración del padrón provincial -lo que contrastaba con la normalidad de la convocatoria y la publicación del padrón nacional para la elección nacional del 7 de abril-, radicales lencinistas y populares le exigieron a Ortega acciones para garantizar la transparencia de los futuros comicios locales. Mientras los primeros pidieron la aplicación lisa y llana de la nueva ley electoral nacional para todas las elecciones a futuro, los populares ponderaron la utilización del padrón nacional y la amplia simpatía de la opinión pública local para con la ley nacional, aunque se mostraron dispuestos a concurrir a elecciones cualquiera fuese la ley que se aplicase (Seghesso, 1981). Asimismo, la Cámara de Diputados

\footnotetext{
${ }^{40}$ Archivo Histórico de Mendoza, Acta de escrutinio de elecciones del 7 de abril de 1912 (distrito electoral Mendoza), carpeta n 16-“Siglo XX”, Sección Electoral, página 51.

${ }^{41}$ Integraban tal junta el Juez Federal con asiento en Mendoza, el presidente de la Suprema Corte y el Fiscal de la Nación. La elección del día 7 tuvo algunas dificultades y debió convocarse a un comicio complementario para el 28 de abril. Sin embargo la prueba se consideró exitosa, tanto por la alta participación (65\% del padrón) como por el triunfo del candidato opositor (el bodeguero Pedro Benegas, del Partido Popular).

${ }^{42}$ En las disposiciones transitorias se estipulaba que no se realizarían elecciones "con arreglo a la ley" mientras no estuviese terminado el nuevo padrón, elaborado sobre la base del Registro Cívico, que debía estar terminado al 31 de diciembre de 1911 (artículos 124 y 125). Se supeditaba así la aplicación de la norma a la convocatoria y posterior labor de las comisiones inscriptoras (Provincia de Mendoza, Recopilación..., p. 1131).
} 
local hizo propio el reclamo por la utilización del registro nacional, enviando una minuta al Poder Ejecutivo en tal sentido. ${ }^{43}$

Finalmente, advirtiendo la imposibilidad de contar con el padrón provincial terminado con suficiente antelación, y dada la inminente realización de elecciones de legisladores provinciales (previstas para el 26 de mayo de 1912), Ortega envió a la Legislatura en febrero un proyecto para adoptar el padrón nacional y la libreta de enrolamiento, esta última como equivalente a la "partida cívica" exigida a nivel local. Ello quedó ordenado por medio de la ley $\mathrm{n}^{\circ} 585$, del 12 de marzo de $1912 .^{44}$

En el mensaje del proyecto reconoció el gobernador que las comisiones habían trabajado regularmente entre noviembre de 1911 y febrero de 1912, pero que el padrón no se hallaba aún "definitivamente terminado" y tenía menos inscriptos que el nacional. Aunque advirtió que las próximas elecciones locales tendrían carácter de "ensayo", conforme él había previsto, ${ }^{45}$ adujo haber escuchado el clamor del Partido Popular y de la Cámara de Diputados pidiendo la adopción del padrón nacional. En virtud de ello, señaló que su intención siempre había sido dar las mayores garantías posibles en materia de sufragio y que accedía al pedido "a fin de que la provincia realice en forma real e intensa la democracia creada por la Constitución". 46

\section{La transposición de la "Ley Sáenz Peña” a la legislación de Mendoza: la ley n 589}

Luego de avenirse al reclamo por la utilización del padrón nacional, Ortega envió un nuevo proyecto a la Legislatura, estipulando la adopción -para las elecciones provinciales de mayo- de los mismos lugares de votación y autoridades de mesa dispuestos para la elección del 7 de abril. Sin duda, esto era fruto de la percepción general de "corrección" de tales comicios nacionales pero también un corolario -necesario en el plano jurídico- de la ley $\mathrm{n}^{\circ}$ 585. Ello se debe a que la excepción de dicha norma creaba una situación de irregularidad

\footnotetext{
${ }^{43}$ A fines de febrero, el diputado sanrafaelino Guillermo L. Aguirre impulsó como moción en la cámara baja la implementación del padrón elaborado por la junta nacional, manifestando la necesidad de "secundar la alta política" del presidente y recibió apoyo unánime de todo el cuerpo. En el cierre de su alocución expresó: "Escuchemos la voz del pueblo, porque es el pueblo quien nos ha de dar la autoridad y el prestigio que necesitamos para que sea fecunda la representación que ejercemos". El Debate, 29-02-1912.

${ }^{44}$ Provincia de Mendoza, Recopilación, pp. 1148-1149. El proyecto es presentado el 29 de febrero y la ley se sancionó el 12 de marzo de 1912, con el voto de los Partidos Unidos.

${ }^{45}$ El carácter de sondeo de los primeros comicios se vislumbra en dos de las disposiciones transitorias de la ley $\mathrm{n}^{\circ} 567$, por las cuales se preveía la utilización del padrón nacional si los plazos originales para completar el Registro Cívico no se podían cumplir (artículo 126) y se facultaba a la Junta Electoral local a modificar por única vez plazos y fechas prescriptos en la ley merced a "inconvenientes imprevistos" (artículo 127). Provincia de Mendoza, Recopilación ..., pp. 1131-1132.

${ }^{46}$ Provincia de Mendoza, Recopilación..., pp. 1146-1147.
} 
funcional para la Junta Electoral local, en tanto sus atribuciones legales se restringían -según ley 567- a la conformación de mesas sobre la base del Registro Cívico provincial, pudiendo tal incongruencia generar reclamos de validez de los comicios a posteriori.

En el mensaje del nuevo proyecto, Ortega manifestaba su intención de repetir -por única vez- los lugares de votación y las autoridades de mesa designados por la Junta electoral nacional para los comicios abrileños. Reconocía que el padrón provincial no brindaba suficientes garantías para el libre sufragio y admitía que con el padrón nacional la acción de la Junta creada por ley 567 se vería "estorbada por inconvenientes de orden legal y de orden práctico", pues se crearían mesas por fuera del padrón original. A partir de ello, entendía que era preciso prevenir posibles cuestionamientos. Sin embargo, defendía la vigencia de los procedimientos de la ley provincial vigente para llevar adelante los comicios, calificándolos como "más sencillos y de más fácil aplicación” que los de la norma nacional.

Se vislumbra que el propósito de Ortega era dar unidad y solidez a los procedimientos -en el marco de la incoherencia normativa generada-, pero no estaba dispuesto a la abrogación de la ley 567, pues ello implicaría invalidarla de antemano y desconocer sus virtudes y la mayor eficacia de sus procedimientos, antes de su primer "ensayo".

Sin embargo, en el recinto legislativo se manifestó la astucia política del civitismo y se saboteó la intención del gobernador, haciéndose eco de los reclamos de la oposición. En forma coordinada, el senador César Ponce y los diputados Federico Corbin y Eliseo Marenco $^{47}$ promovieron desde las comisiones de Legislación de sus respectivas cámaras -en el marco de la potestad parlamentaria de revisión del proyecto del Ejecutivo- un cambio drástico de rumbo, alejándose del objetivo primigenio del mismo. ${ }^{48}$

A partir de ese giro, se terminó sancionando una reforma integral de la ley electoral provincial, que respondió al clima de opinión favorable a la utilización de la ley nacional. Sin

\footnotetext{
${ }^{47}$ José César Ponce Roig (1858-1916) era hijo del militar, periodista, político y poeta José Rudecindo Ponce. Se recibió de abogado en Buenos Aires y fue un profesional de renombre en el foro local, además de músico aficionado. Resultó elegido senador en 1910, en representación del departamento de Junín, apadrinado por Civit; Federico Jorge Corbin (1867-1930) era un médico cirujano, de origen canadiense, que llegó a la provincia en 1899 y se convirtió en pionero de la medicina local. Fue nombrado jefe de servicio del Hospital Provincial por Civit desde su creación en 1907 y luego fue electo diputado provincial, en 1909. Además fue Vicepresidente de la Constructora Andina y miembro de la Comisión de Fomento frutícola; Eliseo Marenco Aberastain (nacido en 1876) era hijo del ex gobernador Eliseo W. Marenco, se había doctorado en jurisprudencia y era profesor del Colegio Nacional de Mendoza. Se vinculó al Partido Liberal civitista y en 1910 fue elegido diputado provincial. Ferviente liberal, integró una logia masónica local y en 1913 dirigió el periódico "La Patria".

${ }^{48}$ Si bien Aguilar omite este giro en el trámite parlamentario y sindica a Ortega como propulsor de la adopción de la ley nacional, nuestra reconstrucción valida el testimonio de Peña y Lillo, a quien damos mayor crédito además por tratarse del vicegobernador y presidente del Senado provincial. Creemos que el interés subyacente en el giro operado por el civitismo al proyecto fue la abrogación de la representación proporcional, sistema que amenazaba su predominio en el ámbito parlamentario local. Véase: José Aguilar, Mendoza en los años 1900 a 1916 (Mendoza: D’Accurzio, 1957), p. 27 y Silvestre Peña y Lillo, Actividad política mendocina en los años 1889 a 1914 (Mendoza: Martín Fierro, 1992), p. 107.
} 
duda incidieron en este cambio de rumbo la condición mayoritaria de los Partidos Unidos en ambas cámaras y también los reclamos de la prensa y de todo el espectro partidario en tal sentido, incluso de la facción radical en abstención. Frente a la amplitud de ese consenso, Ortega debió avenirse a derogar la ley $\mathrm{n}^{\circ}$ 567, que había promovido con ahínco. La nueva norma se aprobó el 20 de abril de 1912 y se promulgó dos días después, bajo el número 589.

En concreto, el texto de la ley contenía 11 artículos, que combinaban disposiciones de orden transitorio para las próximas elecciones con otras que salvaban incongruencias entre la adopción del padrón, las autoridades de mesa y los lugares de votación del orden nacional con la normativa local. Sin embargo, en el artículo quinto -sobre el cual se centró la modificación impulsada por los legisladores civitistas- se dispuso una enumeración de una treintena de interpolaciones al texto íntegro de la ley 8.871, junto con otros agregados y supresiones, que adecuaban la terminología de la ley nacional en lo referente a los procedimientos y prerrogativas asignadas a órganos o funcionarios nacionales, para el orden provincial. Asimismo, quedaron subsistentes de la ley anterior los artículos 14 a 16, relativos a la distribución de los distritos electorales y la cantidad de bancas asignadas a cada sección.

El resultado fue una ley híbrida, que dio origen a un nuevo régimen electoral, abrogando la ley $\mathrm{n}^{\circ} 567$-salvo los 3 artículos antedichos- y que reprodujo en esencia la mayoría de los artículos de la ley nacional n 8871, con mínimos agregados, modificaciones o supresiones de términos -necesarios para su adecuación y aplicación en el marco provincial.

A efectos de evitar confusiones, el 22 de abril Ortega dispuso por decreto la publicación de una edición ordenada, que compilase el texto de la norma nacional con las demás interpolaciones que insertaba la ley $\mathrm{n}^{\circ} 589$, incluyendo los artículos subsistentes de la norma anterior y los decretos reglamentarios posteriores. La recopilación se encargó al subsecretario de gobierno, el joven abogado Luciano Peltier. ${ }^{49}$

Se vislumbra así que el nuevo régimen electoral provincial condujo a la adopción lisa y llana de los principios de la Ley Sáenz Peña para los comicios locales, dada la asimilación de la norma provincial con la nacional en el grueso de su contenido.

¿Qué cambios hubo frente a la norma anterior? Respecto de la Junta Electoral local, se modificó su composición, añadiéndose a su integración al Procurador General de la Corte y al Fiscal Público de lo Criminal, dando con ello mayor peso a los representantes "judiciales" frente a los "políticos", que gozaban de mayoría en la ley anterior.

\footnotetext{
${ }^{49}$ Provincia de Mendoza, Régimen Electoral de la Provincia de Mendoza (Mendoza: Establecimiento gráfico «Linotype» de Félix Best, 1912). Jorge Luciano Peltier (1889-1950) fue luego en los años treinta un destacado dirigente del Partido Demócrata Nacional y en 1932 promovió como senador una reforma electoral.
} 
En lo relativo al sistema electoral, se dispuso para Diputados y electores de Gobernador la lista incompleta, aunque no se innovó en la elección de senadores. Subsistieron los distritos y secciones electorales contemplados en los artículos 14 a 16 de la ley 567 y la cantidad de escaños o bancas que allí se fijaban.

En cuanto al comicio, se obvió la exigencia de "doble llave" para las urnas y se descartó el escrutinio parcial en cada mesa. Persistieron, en cambio, la amplitud de criterio de los presidentes de mesa sobre la identidad de los votantes y la exigencia de que no faltasen en el cuarto oscuro las boletas de los diversos partidos, en lugar visible y por separado. Finalmente, en lo que hace a las penas por infracciones a la norma, se adoptó el criterio nacional, pero quedaron los aspectos procesales a cargo de la justicia del Crimen local.

La sanción de la nueva reforma dio lugar a realineamientos político-partidarios que le permitieron a Ortega sacar provecho político de la situación. Tres días después de promulgada la ley, renunciaron en bloque los 3 ministros provinciales, disgustados por la ruptura abierta del gobernador con los Partidos Unidos y por el acercamiento del gobernador a la oposición. En su reemplazo se nombró como Ministro de Gobierno a Barraquero, ${ }^{50}$ a Joaquín Sayanca en Hacienda y a Estanislao Gaviola en Industrias. ${ }^{51}$

En forma paralela, los radicales moderados rompieron la alianza con Civit -los "Partidos Unidos"- y decidieron concurrir por separado a las elecciones legislativas del 26 de mayo, logrando la minoría. Según señala Funes (1942:148), desde entonces el esta facción se convirtió en "partido oficial", en virtud del nombramiento que este hizo de varios radicales en puestos en la administración pública y del presidente de la Suprema Corte de Justicia local -el abogado radical porteño Luis Álvarez Prado-. ${ }^{52}$ Por su parte los populares lograron la mayoría y se perfilaron como principales beneficiarios del incremento de la participación electoral promovido por la nueva ley electoral.

En el ámbito legislativo, populares y radicales moderados articularon -detrás de su aparente competencia interpartidaria- una entente política que minó el poder del civitismo y lo

\footnotetext{
${ }^{50}$ Barraquero se hallaba afiliado al Partido Popular desde su creación, pero se desafilió a este antes de asumir como ministro, buscando dejar en evidencia que su acción se vería orientada apuntalar el programa de libre sufragio del gobernador y no estaría guiada por intereses partidarios.

${ }^{51}$ Tanto Sayanca como Gaviola habían sido dirigentes vinculados al conservadurismo que migraron por entonces al radicalismo moderado. Gaviola tenía como base de actuación el departamento de Rivadavia y había sido candidato a diputado nacional en abril de 1912 por el oficialismo, siendo derrotado por Benegas. Pero en 1914 fue candidato a vicegobernador y a senador provincial por la UCR. Por su parte Sayanca desarrolló una prometedora carrera en la magistratura local y fue precandidato a gobernador en 1921 por la UCR no lencinista.

52 Corresponde advertir que Ortega no se reconoció oficialmente por entonces como radical, y adoptó hasta el final de su mandato una posición de "prescindencia" partidaria equivalente a la de Sáenz Peña. A posteriori, sin embargo, su carrera política quedó vinculada a ese partido: además de ocupar cargos públicos provinciales, fue Diputado Nacional por la UCR (1928-1930) y se lo sindica como el candidato predilecto de Yrigoyen para la gobernación de Mendoza en los años veinte. Pablo Lacoste, Historia de la Unión Cívica ..., p. 36.
} 
fue desplazando paulatinamente de ambas cámaras en las elecciones sucesivas, con aval de Ortega. ${ }^{53}$ Tal entente se mantuvo hasta que el Comité Nacional de la UCR propició en 1913, en el marco del levantamiento de su abstención, la reunificación de las facciones locales.

Por el lado de los civitistas, luego de la disolución de los Partidos Unidos y de su abstención en las elecciones de mayo de 1912, Civit promovió en julio de 1913, la creación de una nueva agrupación -la Concentración Cívica Regional-, con la que se presentó como candidato a gobernador, siendo derrotado por el Partido Popular.

\section{Mendoza: jurisdicción pionera en la adopción del programa reformista}

Los postulados reformistas de Sáenz Peña hallaron un eco favorable en Mendoza y ello derivó en una respuesta temprana de la elite dirigente local, concretada en la modificación de la normativa electoral provincial. Se vislumbra que tal proceso tuvo algunas particularidades que signaron su derrotero y cuyo resultado permite una correlación con las respuestas de otras elites provinciales en materia de reformas electorales.

En primer lugar, la cruzada de Ortega reconoce como antecedente una tradición reformista de raigambre local, encabezada por Barraquero desde varios lustros antes. La provincia contaba así con antecedentes doctrinarios y proyectos de avanzada en materia electoral, que abrevaban en experiencias pioneras de provincias como Buenos Aires y Corrientes. ${ }^{54}$ La ley $n^{\circ} 567$ retomó buena parte de estos precedentes, lo que se observa en el mecanismo de confección del registro cívico, la adopción de la proporcionalidad como sistema electoral y el incremento de penas por incumplimiento de las disposiciones legales.

Un segundo aspecto a destacar es la firmeza del gobierno local a la hora de hacer cumplir la nueva normativa, acción que dio lugar a la realización de comicios que fueron considerados como ejemplares. ${ }^{55}$ Se destaca al respecto en la elite local el mantenimiento de la voluntad de cumplir estrictamente con las disposiciones penales en la materia, lo que permitió gestar prácticas comiciales coherentes con lo que se estipulaba en la letra de la ley. ${ }^{56}$

\footnotetext{
${ }^{53}$ Un ejemplo es la elección de Benito Villanueva como senador nacional por Mendoza en noviembre de 1912 por la Legislatura, impulsado por los populares para contrarrestar a Civit. Este dirigente había nacido en Mendoza pero se hallaba radicado en Buenos Aires, donde regenteaba los negocios ganaderos de su familia y se había desempeñado como diputado y senador nacional por la Capital (1904-1910).

${ }^{54}$ Véase al respecto Leonardo Hirsch, "La República proporcional... y María del Mar Solís Carnicer, "Los conservadores argentinos...

${ }^{55}$ Mario Justo López, De la República..., p. 349, 356, 369 y 373. Al referir a las elecciones legislativas provinciales del 26 de mayo de 1912, destaca este autor que Mendoza fue la primera provincia en realizar una elección "con total corrección, sin la participación del gobierno nacional".

${ }^{56}$ Un observador contemporáneo advertía en 1914 que la provincia de Mendoza era "la única que ha cumplido estrictamente con las prescripciones de la nueva ley electoral, no sólo abriendo el camino de los atrios, sino
} 
En cuanto a los postulados de fondo del programa presidencial, Mendoza fue la primera provincia del país en incorporar en forma irrestricta al orden local el voto secreto y obligatorio junto con la utilización del padrón nacional -elaborado sobre la base del enrolamiento militar- y la acción de la justicia federal en la distribución de mesas y nombramiento de sus autoridades.

Respecto del carácter obligatorio y secreto del voto, se observa un giro significativo, motivado a nuestro entender por el interés de la dirigencia política local -a partir de su adscripción al ideario reformista- en armonizar en forma irrestricta la normativa local con los principios y mecanismos del orden nacional. ${ }^{57}$ Por otro lado, cabe señalar al respecto que, en el espectro de las legislaciones provinciales, el alineamiento de la normativa mendocina resulta temprano, pues el nuevo ordenamiento se promulgó poco después de cumplirse los dos meses de vigencia de la ley $\mathrm{n}^{\circ} 8.871 .^{58}$

En lo que respecta al sistema electoral, se afirma que Mendoza fue la única provincia que adoptó íntegramente el sistema de lista incompleta, ${ }^{59}$ tanto para la elección de diputados como para la de gobernador y vice, en este último caso por medio de una Junta de Electores, integrada por un número equivalente al total de diputados y senadores, sobre la base de los mismos distritos de la cámara baja. ${ }^{60}$ Sin embargo, corresponde hacer la salvedad respecto de la elección del Senado provincial, que continuó siendo a simple pluralidad. En ese marco, se limitaba la probabilidad de que hubiera más de dos partidos representados en la Legislatura: para Diputados ello era factible si triunfaban o lograban minoría dos partidos distintos en al menos dos distritos distintos. Pero para el caso del Senado, en cambio, esto era más difícil,

haciendo efectivos los castigos a los infractores". Agregaba, además, que el caso cuyano era así "la excepción en la regla, puesto que las demás provincias continúan gozando de sus garantías constitucionales sin la ingerencia [sic] federal", y gracias a ello sus elites "siguen tan frescas haciendo lo que se les da la gana en material electoral". Wenceslao Molins, Patogenia política (Buenos Aires: Larrea, 1914), pp. 43-44.

${ }^{57}$ En lo relativo a la calidad de elector, hemos aludido a las preferencias de la elite dirigente de mediados del siglo XIX y luego de doctrinarios como Julián Barraquero por el voto calificado. Sin embargo, con la ley 589 el ordenamiento local ratificó la universalidad del sufragio, tal como se venía reconociendo en el país desde la primera ley electoral nacional, principio respecto del cual la Ley Sáenz Peña no innovó. Entendemos que el giro respondió al carácter extemporáneo de la inclinación al voto calificado, en tanto este resultaba no sólo contrario a la legislación nacional, sino divergente respecto de la vocación aperturista del programa presidencial y de su interés por superar la apatía electoral por medio del voto obligatorio.

${ }^{58}$ Si bien cronológicamente la primera ley es la de Tucumán (ley provincial número 1103, del 9 de febrero de 1912), dicha norma no contemplaba la obligatoriedad del voto, uno de los pilares de la reforma saenzpeñista.

${ }^{59}$ Mariano Fabris, Mauro Ferrari y Héctor Barbero, El proceso..., p. 80

${ }^{60} \mathrm{La}$ elección indirecta de gobernador y vice permaneció vigente hasta la reforma constitucional de 1916, cuando se consagró en su artículo 120 la elección directa. En referencia a este resguardo, advierte Molins que la ley mendocina resultaba más anticuada y menos democrática que la norma de San Juan, donde se consagró tempranamente la elección directa. Carlos Egües, Historia constitucional... p. 96 y Wenceslao Molins, Patogenia..., p. 36. 
pues implicaba que en más de un departamento o en la Capital un partido minoritario se impusiese al candidato del oficialismo y lograse la banca senatorial en juego.

Asimismo, corresponde destacar que la consagración del sistema de lista incompleta adoptado en el orden nacional implicó la supresión de la representación proporcional, plasmada en la ley $n^{\circ} 567$. Tal preferencia abrevaba en las aludidas propuestas de Barraquero y dicho sistema tuvo vigencia efectiva en la provincia entre 1895 y $1900 .{ }^{61}$ Cabe advertir que la equiparación de la elección de integrantes de otros cuerpos colegiados (convenciones constituyentes y concejos deliberantes) conllevó la implementación de la lista incompleta para tales cargos, impidiendo la ampliación de la representación a otras fuerzas minoritarias incluso en el ámbito municipal. En este último, la normativa mendocina se alejó de lo dispuesto en jurisdicciones como Entre Ríos, donde los espacios municipales fueron elegidos para "hacer escuela" en relación al régimen proporcional. ${ }^{62}$

Por otro lado, en lo que hace a la cantidad diferente de escaños asignados a cada distrito, Fabris, Ferrari y Barbero ponen como ejemplo la desigualdad entre población y escaños en 2 secciones mendocinas, dejando entrever en ello una acción deliberada de "malapportionment". ${ }^{63}$ Mientras el primer distrito contaba con 76.103 habitantes y elegía 8 representantes, el segundo distrito -con una población de 113.633 habitantes- sólo elegía un representante más, o sea 9 . Si añadimos información del tercer distrito -que elegía 8 diputados y tenía 87.519 habitantes ${ }^{64}$ - se ratifica la diferencia numérica favorable al primer distrito.

Entendemos que tal diferencia pudo responder a la necesidad de dar mayor equilibrio a la cámara baja, en virtud de la composición del Senado. El cálculo numérico muestra que en dicha cámara -hecha la salvedad de su integración por departamento- al primer distrito correspondían sólo 3 senadores, mientras que el segundo aportaba 7 y el tercero 6. Aunque este desfasaje se ve relativizado si consideramos que muchos miembros de la clase dirigente

\footnotetext{
${ }^{61}$ Cabe señalar en este punto que la Constitución local no contenía disposiciones restrictivas respecto de la proporcionalidad, como sí sucedió con el artículo 37 de la Constitución Nacional, que estipulaba taxativamente la elección de diputados "a simple pluralidad de sufragios".

${ }^{62}$ Nicolás Motura, "De la República Restrictiva..., p. 36.

${ }^{63}$ Mariano Fabris, Mauro Ferrari y Héctor Barbero, El proceso..., p. 75. Se entiende por tal la existencia de un desfasaje entre el porcentaje de escaños asignado a un distrito y la población del mismo en relación con otras jurisdicciones, lo que deriva en que unos estén sobrerrepresentados y otros infrarrepresentados. Véase: Julio César De la Vega, Diccionario consultor político. (Buenos Aires: Librex, 1987). Un claro ejemplo de manipulación del distritado lo brinda el caso de Corrientes (María del Mar Solís, "Los conservadores..., p. 82).

${ }^{64}$ República Argentina, Tercer Censo Nacional, levantado el 1 de junio de 1914 (Buenos Aires: Talleres Gráficos de L.J. Rosso y Cia, 1916), tomo II, pp. 70-73.
} 
que tenían su residencia en la Capital contaban también con propiedades rurales en el segundo o tercer distrito, y merced a ello terciaban igualmente en la representación. ${ }^{65}$

Otra singularidad es la implementación de la lista abierta, en una reformulación del criterio de la ley 567 (que posibilitaba al votante armar su propia boleta combinando candidatos de distintas listas proclamadas por la Junta Electoral). La novedad estriba aquí en la posibilidad de "agregar nombres" (sin que figurasen en listas de los partidos). En este caso, se contabilizaba el voto sólo para los primeros -conforme al orden en que figurasen inscriptoshasta completar el número legal según los cargos en juego en la convocatoria. Sin duda, esto daba al elector mayor libertad para dar curso a sus preferencias electorales.

Igualmente se ha destacado la forma de integración de la Junta Electoral en la provincia. Por el artículo 39 de la ley 589, quedaba constituida por cinco integrantes, dos de los cuales eran miembros del poder político: el Presidente del Senado y el Presidente de la Cámara de Diputados. ${ }^{66}$ Merced a esta fracción "política” de la Junta, Mendoza se diferenció del orden nacional, que excluyó por completo a autoridades con nexos partidarios en su seno. ${ }^{67}$ Se reiteraba el criterio establecido en la ley n ${ }^{\circ} 567$ y de la Constitución de 1910 (que integraba de igual modo la Junta que debía proclamar al gobernador). ${ }^{68}$

Otras especificidades del nuevo régimen tienen que ver con el acto comicial, entre ellas la disposición de los lugares de votación por parte de la Junta Electoral local o la responsabilidad asignada a esta última en el envío de los padrones a las mesas de votación.

Por último, respecto de la aludida amplitud de criterio concedida a las autoridades de mesa a la hora de dar por válida la identidad del votante, es preciso aclarar que la ley estipulaba que no podía impedírsele el voto a una persona cuyos datos no coincidían con los del padrón cuando fuese posible determinar su identidad por otras vías alternativas. Fabris, Ferrari y Barbero argumentan que con ello la ley mendocina otorgaba al presidente de mesa

\footnotetext{
${ }^{65}$ En el marco del amplio dominio ejercido por ciertas familias de la oligarquía sobre vastos espacios del territorio provincial en la época, algunas figuras podían incidir en los resultados electorales por medio de la influencia sobre el voto de sus dependientes directos en fincas o estancias (sirvientes, contratistas y/o peones) o bien por sus acciones de beneficencia, su colaboración con las necesidades de las poblaciones rurales. Respecto de esto último, resulta ilustrativo el dominio que ejercían clanes como los Ortega en Malargüe (por entonces departamento de San Rafael) o la familia de Angelino Arenas en el departamento Santa Rosa. Jaime Correas, Historias de familias... pp. 39-49.

${ }^{66}$ Los otros integrantes eran el Presidente de la Suprema Corte de Justicia provincial, el Procurador de dicha corte y el Fiscal Público en lo criminal. Provincia de Mendoza, Régimen Electoral..., p. 25.

${ }^{67}$ En el orden nacional, la ley 8.871 preveía en su artículo 51 la constitución en cada capital de provincia de una junta escrutadora nacional, integrada por el presidente de la Cámara Federal de Apelaciones, el juez federal y el presidente del Superior Tribunal de justicia de la provincia respectiva. La presidencia correspondía al magistrado de mayor jerarquía en el orden tribunalicio y la junta requería de la totalidad de sus miembros (quórum pleno) para adoptar sus resoluciones. Fuera de Mendoza, sólo en Santa Fe se adoptó una integración con presencia de miembros "políticos”. Marcela Ferrari, De la nación ..., p. 202.

${ }^{68}$ Artículo 71 de la Constitución de Mendoza de 1910. Este criterio se mantuvo en reformas posteriores, con lo cual cabe pensar en un amplio consenso de la clase dirigente mendocina en torno a tal composición.
} 
un poder de decisión que excedía sus facultades e incluso Ferrari habla de "discrecionalidad". ${ }^{69}$ Sin embargo, cabe pensar que el sentido de la disposición era no impedir de antemano el voto al elector en el momento, pero ello podía ser observado a posteriori por los partidos, dado que el presidente debía dejar salvedad por escrito de la impugnación identitaria, tanto en el registro como en un papel aparte, que se introducía dentro del sobre de ese votante. Al eliminarse el escrutinio parcial previsto en la ley 567 , la validez de dicho voto quedaba a criterio de la Junta escrutadora provincial en el escrutinio general.

\section{Consideraciones finales}

Luego de una fallida reforma electoral promovida en 1911, la "Ley Sáenz Peña" fue receptada en la ley mendocina de abril de 1912, mediante un procedimiento que implicó la reproducción literal del grueso de su redacción, haciendo de Mendoza la primera provincia en acoger sus postulados fundamentales para las elecciones locales. La forma híbrida de la norma resultante tuvo origen en un golpe de timón, provocado por un artilugio en el trámite parlamentario, que respondió tanto a la inaplicabilidad de la ley anterior -por sus dificultades intrínsecas- como a los reclamos de la oposición en la coyuntura político-electoral de marzo de 1912. Esto muestra que hubo una predisposición favorable de todo el espectro partidario y de la dirigencia local a la aplicación de los nuevos principios, tanto para elecciones nacionales como para las provinciales.

Sin duda, un factor clave fue la debilidad política del gobernador Ortega -huérfano de respaldo partidario por su ruptura con Civit- y su intención de emular en la escena local la postura de prescindencia partidaria de Sáenz Peña. En ese marco, cupo a este dirigente el mérito de hacer cumplir con eficacia las nuevas reglas de juego, más allá de la letra de la ley, haciendo de la provincia un caso ejemplar en la aplicación de sanciones al incumplimiento de las garantías para el libre sufragio. Tal conducta se explica también en virtud del consenso generalizado favorable a la reforma y del giro significativo operado en su trayectoria política: se trata del hijo de un ex gobernador y miembro de la oligarquía local, que accedió al poder de la mano del civitismo, pasando en la coyuntura analizada a la ruptura definitiva con este y a la adopción sincera del ideario reformista, para concretar luego su conversión al "credo" radical.

En cuanto a la ley de 1911, se vislumbra que su excesivo reglamentarismo obstaculizó la aplicación de sus principios y provocó sospechas del arco opositor sobre la sinceridad de la

\footnotetext{
${ }^{69}$ Mariano Fabris, Mauro Ferrari y Héctor Barbero, El proceso..., p.78; Marcela Ferrari, De la nación..., p. 201.
} 
voluntad reformista de Ortega. Cabe advertir a partir de ello que la "cuestión electoral" implicó un desafío no menor para los incipientes planteles burocráticos provinciales, lo que exigió un refuerzo en la dotación de recursos y personal, en vistas a hacer frente con eficacia a los nuevos mecanismos y acciones necesarias para garantizar la pureza del sufragio.

Por otro lado, lo analizado respecto de la morfología de la ley de 1912 en relación con sus aspectos técnicos (carácter del voto, calidad de elector, sistema electoral, integración y atribuciones de la Junta Electoral y otras cuestiones relativas al acto de votar) permite matizar algunas apreciaciones expresadas en estudios sobre las normativas provinciales e invita a profundizar en un abordaje comparativo integral, que tenga en cuenta antecedentes legislativos, estructura del marco normativo y contexto histórico de los procesos de reforma en los escenarios subnacionales.

La recepción precoz del ideario reformista permite ubicar a la elite dirigente mendocina dentro de los elencos que se alinearon a favor de la reforma nacional, operando desde los "márgenes al centro", en la línea de lo planteado por Míguez en la cita incorporada al principio del trabajo. Esto reafirma la importancia de evaluar cómo reaccionaron las élites locales frente a la reforma nacional -más allá de sus expresiones retóricas-, y coloca a las legislaciones provinciales como una variable de análisis clave para evaluar su conducta, junto con las prácticas electorales concretas y la aludida cuestión del castigo a las infracciones.

Finalmente, corresponde advertir que en Mendoza el derrotero reformista continuó abierto: entre 1915 y 1916 tuvo lugar la reforma de la Constitución provincial -que impuso la elección directa del gobernador y modificó la forma de integración Senado- y luego, en 1920, el radicalismo local -encabezado por Lencinas- sancionó su propia ley electoral.

A partir de ello, creemos que la reconstrucción de la respuesta de las elites lugareñas al programa saenzpeñista y el abordaje de la modalidad de recepción que dicho programa tuvo en la letra de las normativas electorales locales invita a una mirada de mediano plazo en torno a la "cuestión electoral" y habilita también a la prosecución de estudios sobre la evolución del marco jurídico y de otras transformaciones operadas en las prácticas electorales y la cultura política, que se dieron a posteriori en las provincias, en sintonía -o no- con la legislación nacional. 